\title{
Silvana Martino
}

Lic. en Trabajo Social, UNR. Becaria CONICET (2005), con sede de trabajo en FLACSO. Estudiante de Maestría con Mención en Ciencias Sociales, FLACSO. Estudiante de Doctorado Humanidades y Artes con Mención en Antropología., Facultad de Humanidades y Artes, UNR.

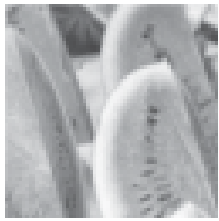

\section{Mapeando Facciones y Liderazgos al Interior de un Complejo Habitacional El conflicto entre facciones}

RESUMEN En el presente artículo se analizan las formas de organización del poder en un determinado enclave urbano articuladas en relaciones conflictivas que redefinen los espacios simbólicos del habitar. Estas permiten poner en entredicho las construcciones sociales del estigma sobre determinadas poblaciones.

PALABRAS CLAVES Facciones - Territorializacion - Politicas de Vivienda - Fonavi - Complejo Habitacional

\section{Introducción}

El presente trabajo ${ }^{1}$ se basa en el análisis de las distintas relaciones que se van entretejiendo en un espacio social, donde se van diseñando lugares para los actores que las corporizan, para la construcción de una historia que sirve de contexto a esas relaciones y a esos actores, y para la definición de grupos y liderazgos al interior de la misma.

Interesa poder recuperar de este entramado de relaciones, los conflictos de poder que se dan entre los distintos grupos en un complejo habitacional urbano. Unos nucleados en torno a la administración de uno de los consorcios, otros reunidos en torno a apellidos, asociados a lo peligroso y lo delictivo, y otro, con la responsabilidad pública de garantizar un orden formal, la policía, inserta en el complejo a partir del

${ }^{1}$ Este se constituye en un recorte del trabajo del que forma parte. El cual supuso un trabajo de campo etnográfico en uno de los Complejos habitacionales FONAVI de la ciudad de Mar del Plata, como becaria del proyecto de investigación Secyt- FLACSO «Violencia, sociabilidad y cultura política en conglomerados urbanoS». PICT 04-06669 (año 2002-2004). 


\section{Silvana Martino}

dispositivo de destacamento.

Estos conflictos delimitan fronteras simbólicas y físicas dentro de ese mismo espacio, dando lugar a la puja por la construcción de distintas nociones de poder y orden. Y a su vez, permiten romper con cierta idea de estigmatización homogénea que opera sobre estas determinadas poblaciones.

En estos tres grupos no se agota la complejidad del conflicto que se reedita a diario, pero sí en estos tres operan ciertos códigos que a la vez de identificarlos mutuamente como enemigos, comparten ciertos rasgos de liderazgo que hace que los demás habitantes les teman. En el discurso de los lideres de estos grupos, aparece la idea de enemigo con el cual no es posible convivir, ni compartir espacios territoriales, aunque el sentido de pertenecer y trabajar en cada uno de los grupos se construye a partir de existir este otro, identificado como enemigo.

Para este análisis parece valioso introducir el concepto de facciones, en tanto puja política entre grupos que disputan su hegemonía en la obtención de ciertos recursos, simbólicos y/o materiales y que nos permite pensar en una realidad en permanente construcción protagonizada por sujetos que desde sus prácticas pretenden modelarla en una lucha que nunca se agota.

El gobierno del territorio, delimitación formal y simbólica del complejo habitacional y las zonas al interior de éste, se constituye en la base del conflicto, en tanto control, delimitación y resignificación de prácticas y representaciones.

A. Isla en su trabajo Los usos políticos de la identidad, para dar cuenta de las facciones, toma de un trabajo clásico ${ }^{2}$ la definición de ésta por cinco elementos: 1- las facciones son grupos en conflicto y que emergieron como parte y razón de la rivalidad; de allí que siempre existe mas de una facción; 2- las facciones son grupos políticos; puntualizando el tipo de conflicto político en el que se desenvuelven los factores; 3- las facciones no son grupos corporativos; 4- los miembros de las facciones son reclutados por un líder; 5 - los miembros de la facción son reclutados siguiendo diferentes principios, como el parentesco, las relaciones de patrón- cliente, identidades religiosas, étnicas, etc. ${ }^{3}$.

Para la organización de las facciones, se necesita de la figura de un líder "una sociedad que no tuviera líder, es decir alguien que habla, estaría incompleta por que es necesario que la figura del poder eventual no se pierda"4. Este lugar tiene que ser definido; se necesita a alguien de quien se pueda decir: «el jefe es él» La gente necesita que él hable por ellos, necesita un portavoz, un negociador, y precisamente estas aptitudes las tiene el jefe.

Uno de los mecanismos mas importante de poder es la redistribución, esta se constituye en una de las funciones fundacionales de todo liderazgo, ya que es el líder el que distribuye el poder y la responsabilidad entre los miembros de su grupo. Esta distribución juega un papel importante en la toma de decisiones y, por lo tanto, también en el apoyo que el grupo le otorga.

Entonces, como el liderazgo está en función del grupo, es importante analizar no solo las características de este sino también el contexto en el que el grupo se desenvuelve y al propio grupo que lo sostiene.

\footnotetext{
${ }^{2} \mathrm{~A}$. Isla cita el trabajo clásico de Nicholas Ralp, Factions: a comparative análisis.

${ }^{3}$ ISLA, A. Los usos políticos de la identidad. Indigenismo y Estado. Buenos Aires, FLACSO - CONICET, 2002, p. 78.

${ }^{4}$ CLASTRÉS, P. «Pierre Clastrés entrevistado» en: Revista Civilización, México DF, 1980.
} 
Pero aquí, retomemos una de las preguntas que sugiere Isla. ¿Cuál es el interés de los miembros de nuclearse en una facción? Es muy simple: la obtención de beneficios para quien los solicita. A partir de la solicitud y frente a la promesa del líder de iniciar los trámites de su demanda, el solicitante como los miembros de su hogar deben lealtad al cacique. Los secuaces establecen así con el líder una relación transaccional.

\section{Mapeando las distintas facciones en juego La organización vecinal: los consorcios}

Una de las facciones que comparten el entramado de relaciones que constituye el Complejo habitacional, está organizada sobre la base formal de la administración consorcial, constituida fundamentalmente por un grupo reducido de familias, quienes comparten y consensúan formas de relacionamiento y dependencia con un líder con características autoritarias. Por esto nos interesa privilegiarla, en un primer momento, para el análisis de las prácticas y representaciones que supone este tipo de liderazgo ligado al autoritarismo, en contraposición a otro tipo de liderazgo, más democrático, paternalista ${ }^{5}$, para después situarlos en el contexto de las facciones.

Este tipo de autoritarismo se caracteriza por construir discursos y prácticas patentizadas, de forma explícita, en un momento histórico concreto a nivel de Estado, y que indudablemente han dejado huellas en las representaciones y las prácticas de los sujetos que participaron.

Estas es posible leerlas aún hoy, como herencias de una política general que se impuso a fuerza de golpes y en nombre de un orden necesario.

La pregunta que cabría plantearse es como después de casi 25 años de democracia todavía sobreviven este tipo de liderazgos, sostenidos en el poder, por sujetos concretos. Pero para no correr riesgo de simplificar el análisis, aventurándonos a encontrar una relación inmediata entre la dictadura y una forma de liderazgo, aislando y determinando a los sujetos que lo ejercen, nos valemos de algunas preguntas que Pierre Clastrés ${ }^{6}$ señala como fundamentales para entender la relación mando- obediencia ¿por qué obedecen?

Esta pregunta la podemos situar en sus dos aspectos, que nos permite complejizar así el análisis, en por lo menos dos niveles: el primero es ¿cómo ocurre que en un momento dado y en un lugar especifico una persona diga "Yo soy el jefe y

\footnotetext{
${ }^{5}$ Basándonos en la diferenciación, que plantea Harris, entre cabecillas, jefes y grandes hombres, nos permite pensar en las diferencias en el liderazgo que se ponen de manifiesto en una organización consorcial del complejo habitacional y vemos coincidir en que el punto central para la definición de estos tipos está puesto en la redistribución. El cabecilla parece engatusar, arengar e implorar desde la mañana hasta la noche. Si hay que hacer alguna tarea, él es el que la inicia y también quien trabaja más duro en ella. Además, el cabecilla no sólo debe dar ejemplo de laboriosidad, sino también de generosidad. Después de una expedición de pesca o caza, se espera que regale más que nadie; si se obtienen artículos de comercio, debe tener cuidado de no quedarse con las mejores piezas para si. Como hemos visto, con frecuencia los cabecillas actúan como intensificadores de la producción y redistribuidores. Consiguen que sus parientes trabajen más, y recogen el producto extra para repartirlo. Es posible que en una misma aldea vivan varios cabecillas y, en los casos en que las condiciones tecnológicas y ecológicas estimulan la intensificación, puede surgir entre ellos un considerable grado de rivalidad. Compiten entre sí para celebrar los festines más generosos y redistribuir las mayores cantidades de bienes A menudo, los redistribuidores más afortunados se gana la reputación de «grandes hombres». HARRIS, M. Antropología Cultural. Madrid, Alianza, 1983.

${ }^{6}$ CLASTRÉS, P. Op. cit.
} 


\section{Silvana Martino}

ustedes van a obedecer"; el segundo, el que corresponde a la base de la pirámide es ¿por qué la gente acepta obedecer a un hombre o a un grupo de hombres cuando estos no tienen una fuerza, un potencial de violencia suficiente como para sembrar el terror en todos ellos?

Coincidimos con Harris" en que "el líder es un producto no de sus características, sino de sus relaciones funcionales con individuos específicos en una situación específica", para pensar en una relación de necesariedad, difícil de aislar para su reflexión.

A la pirámide que plantea Clastrés para organizar la dupla mando obediencia, es necesario complejizarla, con la idea de poder,

"¿Para que quiere uno el poder si no es para ejercerlo? El poder pierde su razón de ser cuando es ejercido ¿Cómo se ejerce el poder? Obligando a los demás a trabajar para uno mismo. El primer acto de quien tiene el poder es exigir tributo a quienes están sometidos a él. Pero... ¿por qué la gente obedece aunque es mucho más fuerte y numerosa que el que manda?"8.

El administrador del consorcio que nos interesa analizar aquí, el consorcio con mayor densidad poblacional, lleva adelante su gestión prácticamente desde el inicio de la ocupación del complejo, llevando adelante prácticas diferenciadoras con respecto a los demás administradores que le permitieron sostenerse en el poder hace 20 años, no pudiendo ser derrocado ni sometido a asambleas, para su renovación.

Para esto cuenta con un discurso y herramientas propias del autoritarismo de estado, arraigadas en su participación en la última dictadura, que le permiten aún hoy valerse de vínculos con instituciones y personajes por fuera del Complejo que lo estabilizan en su cargo. Para esto se vale de herramientas y vínculos con la fuerza policial departamental, reforzando la representación autoritaria y represiva, y a su vez quedando en claro las vinculaciones con este tipo de instituciones a las que llama «deudas reciprocas» entre las «fuerzas del orden» y él.

Acerca de las formas de legitimar la autoridad, Isla sostiene que ésta se asienta en la capacidad de las personas que se consideran líderes, en imbricar mundos muy diferentes con distintas lógicas, mediante un tráfico de favores e influencia, que muchas veces quedan como gestos convincentes de prestidigitación, sin un probable sustento real ${ }^{9}$. Estas relaciones extra complejo que el administrador apela, parecieran no tener ningún sustento real, pero necesita enunciarlas a nivel de discurso para la reproducción simbólica del poder que legitima su lugar.

Más adelante, Isla sigue, "la autoridad es lograda por el cacique y conferida por los miembros a través de la astucia. La astucia para moverse en muchos mundos simultáneamente, lograr negociaciones fructíferas en ellos, en provecho de los miembros de la facción, o de otro por reclutar, es la cualidad mas importante que se requiere del jefe"10.

Si bien, el autor analiza el liderazgo en comunidades indígenas y por esto la imbricación de mundos, nos resulta interesante la relación transaccional que se esta-

${ }^{7}$ HARRIS, M. Op. cit.

${ }^{8}$ CLASTRÉS, P. Op cit.

${ }^{9}$ ISLA, A. Op. cit., p. 77

${ }^{10}$ ISLA, A. Op. cit., p. 79. 
blece entre los secuaces y el líder.

Su poder, que es en gran parte su fama, al interior del espacio local, se establece a través de la acumulación de logros para los solicitantes, los cuales son propagandizados velozmente en el conjunto de seguidores y adversarios

Cada logro es amplificado ya que se trata siempre de demostrar sus contactos e influencias con personalidades conocidas del mundo del dinero, la política, la justicia, el estado ${ }^{11}$.

El administrador de dicho consorcio construye su poder en parte, a partir de demostrar las vinculaciones de las que se vale por fuera del complejo, como fuerte legitimación de su cargo, operando simbólicamente en esta construcción en tanto los conflictos no se resuelven internamente sino mediante la apelación a estos espacios o figuras. Así se reproduce por la vía del temor, la lealtad o el silencio.

"No se si tiene amigos más arriba, por que él esta mucho con Aldo Rico, tiene mucha amistad, ¿terrible, no? Entonces la gente le tiene miedo, nadie lo enfrenta. Con el asunto que fue de las fuerzas armadas también se hace valer en ese sentido (...) el habla de igual a igual con las fuerzas armadas"12.

A su vez, construye una relación particular con las familias a partir de la redistribución de la condonación de deudas, que en muchos casos, al no plegarse algunas familias a su autoridad, le costó el desalojo del complejo. Esta condonación de la deuda, bajo la figura de expensas ${ }^{13}$, supone ubicarlo, en la representación simbólica de las familias en el lugar de un semi Dios "a él le debo la vida, gracias a que me perdonó la deuda no nos sacaron de acá".

Así también, la redistribución opera como un mecanismo de poder entre el líder y los miembros del destacamento, en la delimitación de las zonas del rondín ${ }^{14}$, las horas de éste, las horas $\mathrm{Coet}^{15}$, los sumarios internos, son decisiones que concentra el subcomisario encargado del destacamento, para esto debe contar con la aprobación del superior quien se aloja en la fuerza departamental. Pero ésas decisiones muchas veces, en cambio, son tomadas al interior del destacamento, lo que permite la circulación recíproca de favores, que desembocan en mayor lealtad y cubrimiento a la figura del jefe.

Sabemos que, coincidentemente con Clastres, "El líder (...) tiene que reunir varias cualidades para ejercer esa función"16, por esto no agotamos en el desarrollo del presente trabajo las cualidades posibles del líder, reafirmando que este espacio de poder debe ser ejercido también desde cualidades singulares.

Esta seguridad de orden pareciera residir en la condonación de deudas y en los arreglos que el administrador hace con algunas familias a cambio de algún favor,

\footnotetext{
11 Ibidem.

${ }^{12}$ Entrevista realizada a vecina del consorcio que se analiza, durante el transcurso del trabajo de campo año 2002.

${ }^{13}$ Cuota mensual para el mantenimiento de los espacios comunes del consorcio y el pago de la luz que permite el funcionamiento del tanque de agua, el cual abastece a todo el consorcio. Esta cuota difiere de la cuota- deuda de la vivienda, siendo responsables de la cobranza de la primera la administración del consorcio, mientras que de la segunda el Banco Hipotecario.

${ }^{14}$ Las zonas mas pedidas son las de los comercios y mas aún de ciertos comercios fuera del complejo, al sostener relaciones personales o por el cobro de algún canon.

${ }^{15}$ Horas extra pagadas como tal.

${ }^{16}$ CLASTRÉS, P. Op. cit.
} 


\section{Silvana Martino}

el cual es retribuido con servicios diferenciales del resto. Por esto, para éstas familias, se vuelve una amenaza la posibilidad de enojo o el cambio del administrador ya que esto de ser cumplido (el derrocamiento por elecciones o por denuncia) pondría en juego la estabilidad, en tanto deuda perdonada, ganada por algunos.

La reciprocidad mantenida entre los vecinos y el administrador, es lo que además, de la situación geográfica, determina la pertenencia a un sector o no. Estas no son meramente intercambios de servicios y bienes, como muchas veces se define la solidaridad de los pobres sino que constituyen un conjunto de intercambios y una continuidad de formas de relaciones sociales que los vinculan y le dan sentido dentro de un contexto histórico dado. Y estas formas de reciprocidad, unas más fuertes e importantes que las otras, son las que construyen socialmente y le dan sentido a la noción de sector y de división territorial (...) en término de obligaciones entre veci$\operatorname{nos}^{17}$.

"él te lo siembra, uno acá, en aquel edificio, el otro allá... y como les perdona las expensas están propenso a todo....la gente les debe, por eso les exige (...) yo tengo la farola de ahí en frente, por que ahí tiene una chusma, entonces la cuida, en la punta tienen la farola por que abajo tiene otra chusma y la cuida, acá a la vuelta hay otra chusma, hay mucha gente que trabaja con él, aparte de no estar solo él tiene un aval de firma, que lo respalda..." ${ }^{18}$.

Esto ayuda a entender el relativo conformismo de la población respecto a unas estructuras, cuya artificialidad / arbitrariedad no logra develar. La violencia se vuelve difusa y devine omnipresente ${ }^{19}$, "... el sabe todo, tiene toda la información, si participas en política, la vida y obra de cada uno".

Con respecto a esto, el administrador explica:

"Nosotros las controlamos con una red de Vecinos que están, que son una especie de cuadro, con propia voluntad, al servicio del Bien Común, comunitario, consorcial..."

"Nosotros trabajamos celularmente, ellas son las encargadas de recopilar toda la información, para hacerla llegar tanto a la policía, como a gendarmería, o a la Cia, si ven que en tal lugar están acopiando drogas o mercadería robadas elaboran la información para pasárselas a quien corresponda, porque no es tarea nuestra hacernos cargo de esas cosas, nosotros se las damos a ellos para que hagan lo que tienen que hacer"20.

La fuerza del grupo gobernante no reside, pues, tanto en la coacción física como en su traducción en la fuerza de las cosas. El poder al generar realidad genera

\footnotetext{
${ }^{17}$ PUEX, N. «Las Formas de la Violencia en Tiempos de Crisis: Una Villa Miseria del Conurbano Bonaerense» en: ISLA, A.; MIGUEZ, D. (Comps.). Heridas Urbanas. Violencia Delictiva y Transformaciones Urbanas en los Noventa. Buenos Aires, FLACSO-Ediciones de la Ciencia, 2003, pp. 40-41.

${ }^{18}$ Entrevista a habitante del consorcio que se analiza. Realizada en el transcurso del trabajo de campo año 2002.

${ }^{19}$ LECHNER, N. La conflictiva y nunca acabada construcción del orden deseado. Madrid, Centro de Investigaciones sociológicas - Siglo XXI, 1986.

${ }^{20}$ Entrevista al administrador del consorcio al que se hace referencia, realizada en el transcurso del trabajo de campo año 2002.
} 
al mismo tiempo su propia legitimidad. El reconocimiento de la realidad ordenada por el poder ${ }^{21}$.

"En el Consorcio nuestro las cosas se manejan así, Yo creo que la única manera que se mantenga en paz como se mantiene esto, nuestros referentes son muy claros"22.

En la gestión del administrador de este consorcio no aparecen rivalidades, ni competencia, ya que no hay espacios alternativos para la construcción de poderes, quedando algunos intentos en la memoria de quienes lo protagonizaron solo como experiencias en las que se logró, por la vía del temor y la amenaza, el silenciamiento y la paralización. El único espacio posible, y a su vez fundante de las administraciones es la asamblea de los consorcistas, a la cual, desde este consorcio, tampoco se permite el acceso a aquellas familias que no están plegadas a la autoridad del administrador.

El espacio de poder que se construye a partir de ganar o poseer la administración es un factor que moviliza, que posibilita desde la intolerancia o el discenso, la organización de propuestas de resistencia, y de remoción de las autoridades consorciales.

Una posible diferencia, que queda abierta para otros posibles trabajos, son los espacios ganados y cedidos por los administradores de turno, que a su vez no solo permiten la participación de los consorcistas en la toma de la palabra, ésta se plantea de manera ampliada, valiéndose otros instrumentos no tan formales para la toma de decisión, aunque esta sea para destituir a un administrador.

Vale decir, además, que quien asume tal posición dentro de un consorcio, organiza y da sentido a un cierto orden, una cierta manera de vincularse con dicha institución, organizarse y vivir dentro de «su» sector. Esto es un punto fundamental para empezar a trazar líneas divisorias no solo en el sentido geográfico sino en la configuración de espacios simbólicos. Siendo, entonces, el administrador una figura conflictiva o posibilitadora dentro de consorcio donde lleva adelante su gestión.

Otra idea interesante para poder pensar en el orden «impuesto» o consensuado por este administrador, es la idea de legalidad en la que quedan vinculados los consorcistas con dicha organización.

Retomemos la pregunta central: ¿por qué una minoría logra gobernar sobre y contra la mayoría? ¿Cómo ocurre que pocos ganen poder sobre muchos??23.

Más allá de la violencia y del temor pareciera haber otros mecanismos por los cuales se acepta determinada estructura de dominación. La fuerza se ejerce a través de ciertas mediaciones que hacen la transmutación del poder en orden ${ }^{24}$.

Lechner acentúa que el poder de la minoría radica en la capacidad de definir las condiciones sociales de manera tal que sus normas explícitas aparecen acorde a la realidad, o sea, que las condiciones sociales hacen aparecer sus normas como buenas y racionales.

\footnotetext{
${ }^{21}$ LECHNER, N. Op. cit.

${ }^{22}$ Entrevista al administrador del consorcio que se analiza, realizada en el transcurso del trabajo de campo. Año 2002.

${ }^{23}$ LECHNER, N. Op. cit., pp. 41-45.

${ }^{24}$ LECHNER, N. Op. cit., pp. 41.
} 


\section{Silvana Martino}

Parte de esta construcción se basa en lo que definíamos en las primeras hojas, la distribución de favores. Y aquí retomamos la definición, propuesta por Lechner, de valor de orden en tanto, grado de certeza alcanzado, que les permite invertir intereses en el orden establecido, puesto que allí reside la base de legitimidad que lo recrea y ante el cual los consorcistas se encuentran en la posición de deudores con respecto al líder.

"Nunca supimos por qué aquellos que supuestamente le dieron el aval con una firma, aunque dicen ellos que no firmaron eso, es como un poder que le dan que él está autorizado para cualquier cosa, me entendés, ellos son morosos, les hizo firmar ese papel que nunca nadie lo leyó,...él se lava la boca diciendo que tiene no se cuantas firmas, que está autorizado por los propietarios"25.

Pero, la relación no es homogénea dentro del consorcio y sobre todo con respecto a la administración , y para muchos esa relación termina bajo la expresión binaria de amigo - enemigo. Desde la administración estos grupos o familias que se agrupan bajo esta denominación son los que de alguna manera justifican las herramientas mas temidas por todos: el desalojo, la denuncia a «los servicios» y el apriete.

Algunos son quienes pasaron bajo la experiencia de enfrentarse a dicho líder pero todos lo recuerdan como una experiencia en donde quedaron solos, otros, son los grupos de jóvenes y familias, con prácticas vinculadas a la droga y al delito quienes ponen en jacke a diario la «paz del orden» impuesta desde la administración.

Estos últimos hacen uso de todo tipo de «ilegalidad», ya que no solo son los grandes morosos de expensas sino que además, usurpan departamentos vacíos, convirtiéndolos en reductos o escondites.

Para este grupo la distribución de favores bajo la forma de condonación de deuda, queda dada naturalmente, sin existir por esto reciprocidad.

Así queda evidenciada una dinámica propia de esta administración, la manipulación de cierta legalidad, en la cual, desde la visión del administrador, entran muy pocos. Esto se convierte en un punto decisivo a la hora de reclamar o hacer valer algún derecho, y en el modo en que se silencian los mismos.

Las diferencias en el planteamiento y la puesta en práctica de las administraciones es reconocida por los habitantes del complejo como formas distintas del vivir y las posibilidades para hacerlo. Pero todos coinciden en el planteamiento de fuertes malestares, tanto en lo que tiene que ver con las condiciones habitacionales en las que se encuentra el complejo, como las deficiencias edilicias y el vínculo entre los que habitan, volviéndose a demarcar zonas donde la sociabilidad se vulneraliza.

Existe dentro de la territorialización del consorcio espacios físicos problemáticos y que funcionan como espacios simbólicos de la violencia. Estos, concretamente, son los locales de planta baja de los edificios, los cuales quedaron como propiedad del administrador y de algunas familias, es decir, que la posibilidad de ser habilitados para tareas comunitarias o a instituciones de política social fue una decisión del mismo, por lo cual nunca fueron usados.

Actualmente se encuentran vacíos y en estado de abandono, constituyéndose en espacios definidos por los adultos como inseguros al prestarse al ocultamiento de

${ }^{25}$ Entrevista realizada a habitante del consorcio que se analiza, durante el transcurso del trabajo de campo. Año 2002-2003. 
los delincuentes, y así quedan expuestos los transeúntes a todo tipo de ataque.

Estos locales abandonados fueron y son espacios ganados por los jóvenes de dicho sector, siendo sus paredes el testimonio de leyendas y peleas entre cuadros de fútbol, de amores jurados y vengados, de consumo de drogas y sobre todo de fuerte oposición a la policía.

Aparece este consorcio como el desordenado y descontrolado, siendo un territorio sin ley, o mejor dicho, un territorio donde la misma instalación de ésta es el motivo de las pujas entre los distintas facciones, dirimiéndose por la instalación de su propia ley en el mismo territorio.

Se definen nuevas fronteras geográficas y simbólicas de violencia dentro del mismo complejo, apareciendo dentro del entramado de prácticas, representaciones y discursos las instituciones como garantes de un cierto orden y control a partir del cual la población resiste, interpela, propone y consensua con dicho orden impuesto

Esta representación que tienen los habitantes de los otros consorcios, parece contradecirse al encontrarse, desde hace dos años, «territorializada» en el consorcio, la institución de control, el destacamento policial, dependiente de la Departamental Mar del Plata.

\section{Algunos apellidos}

Las disposiciones geográficas de este sector del complejo, no solo por densidad ya que es el que contiene mayor población, sino por constituirse el más «peligroso», está de alguna manera organizado u ordenado por algunas familias «peligrosas». Estas deciden los espacios y momentos de ese sector, representando una amenaza constante para los vecinos quienes se sienten «encerrados» en sus propios territorios.

Aquí tomamos de Goffman la idea de que el individuo muestra en su vida corriente una máscara o fachada que sirve para una puesta en escena de acuerdo con una situación dada y con una personalidad que se forma a partir de pautas culturales propiamente locales y cerradas en torno sus vivencias. Así, este se mostrará ante los demás como él considera que los demás lo ven en relación con su rol y estatus, es decir que trata de actuar de acuerdo con lo que cree que esperan de él.

Esta puesta en escena, siguiendo el análisis de Goffman, se puede realizar individualmente o en equipo; los miembros del equipo se apoyarán mutuamente tanto mediante expresiones verbales como no verbales, pueden ser intercambiables según las necesidades, e incluso si algún miembro no guarda las relativas normas de «complicidad» puede ser eliminado, teniendo como alternativa el posible acceso a otro equipo rival.

La dramatización de los actos se realiza dentro de un entorno físico que se denomina escenario; en él los actores desarrollarán su puesta en escena ante un auditorio, que es el interlocutor al que hay que convencer.

Pero también es cierto que en estos barrios existe una homogeneidad que opera negativamente en la construcción de la representación social del mismo, recreando así un afuera, y un adentro, el cual se reproduce al interior del mismo complejo, territorializando sectores del barrio mas peligrosos e intransitables.

Pareciera que los jóvenes del barrio encuentran en los lazos de un determinado grupo un nuevos orden, al marcar un nosotros y otro, y ese otro pareciera en algún 


\section{Silvana Martino}

punto estar puesto en la policía, re ordenándose los espacios y los vínculos.

Dentro de esa homogeneidad que podrían constituir estos jóvenes, también se encuentran criterios clasificatorios para el agrupamiento de éstos, complejizándose la demarcación posible, aunque insisten y comparten todos la identificación por oposición a la policía.

Pareciera que así se van delineando fronteras simbólicas entre los peligrosos, por «meterse con el barrio», por portar armas, por exhibirlas y entre los pibes que no se meten con el barrio, como una manera de respetar al conocido, al vecino.

Esto permite pensar que hay una cierta legitimidad de valores comunes, reconocibles en las familias que están desde siempre. No así con las familias más jóvenes, que ingresaron al barrio por comprar, o alquilar algún departamento, quienes no son parte de esa primera sociabilidad que se construyó desde el inicio del complejo, hace 20 años. Otra cuestión que está en juego es el cambio generacional, marcado por los mismos chicos, «los pibes de antes» diferenciándose de los pibes de ahora, que nos les importa nada. Estos así rompen con valores ordenadores del adentro y del afuera, sumándose el consumo de drogas como desencadenante para el todo vale.

Uno de los grupos posibles de delimitar estaría definido por apellidos, siendo sus principales participantes quienes pertenecen por vínculos sanguíneos a familias quienes portan determinado apellido. El otro grupo del complejo podría demarcarse no desde el lazo de consanguinidad como factor decisivo para la pertenencia, pero sí el consumo de drogas, y los antecedentes policiales, la ocupación de ciertos espacios geográficos dentro del complejo y el uso de ciertos códigos. En este grupo participan también, los hermanos o hijos más chicos de las familias antes enunciadas.

Ambos grupos reproducen y re-editan el estigma de lo peligroso, sintiéndose los vecinos y los comerciantes del lugar amenazados y expuestos a cualquier ataque.

Frente a la vulnerabilidad a la que se sienten sometidos exigen mayor control, reclamando una determinada práctica y función policial que les de garantías de orden, a las situaciones que se les escapan de las manos.

Pero la existencia de la policía tampoco parece ser garantía de «ley» sobre todo esto queda evidenciado en la figura de uno de los policías. Este se constituye en un figura conflictiva, funcional a un sistema que lo produce y lo contiene, para determinadas acciones. Esta figura será motivo, a partir de una situación puntual, de fuertes tensiones al interior del destacamento como con los vecinos y a quienes los chicos apodaron Bin Laden ligándolo a lo peligroso.

"Bin Laden fue el que le tiroteó a los Sanchez ${ }^{26}$ se las tenía jurada...acá todos sabíamos, sabé como estaba la familia, eran la 1 y no se sabía nada, ni siquiera le tocaban la puerta para decirles algo bueno o algo malo, acá se comentaba desde temprano que habían salido a hacer un trabajito"27.

Este grupo, el de los más chicos, exige y hace valer una territorialización física, donde materializan sus encuentros, donde se llevan adelante los rituales, apro-

\footnotetext{
${ }^{26}$ Los nombres propios han sido cambiados para preservar la identidad de los habitantes del barrio.

${ }^{27}$ Entrevista a habitante del complejo habitacional durante el trabajo de campo. Año 2002-2003.
} 
piándose de un espacio simbólico para resignificarlo.

Es así que aparecen «el medio» y una escalera en particular, como los lugares convocantes. Paradójicamente estos espacios se encuentran a metros del destacamento policial, pero dada su disposición les permite visualizar primero el paso de un «rondín» policial y así amontonarse en una escalera frente al peligro de ser vistos durante la realización del consumo colectivo de drogas, o simplemente por portar rostro.

«El medio» es un lugar abierto, encontrándose, como lo indica su nombre, en el medio de un circulo de edificios, sirviendo de espacio público de conexión entre los edificios y como lugar de recreación.

"Ni siquiera, en cualquier plaza del barrio se puede estar, por que llegan ellos (la policía del destacamento) - y te dicen: tomátela, metete en tu cucha que acá mando yo."

Es así como la oposición a la policía les permite constituirse como un colectivo, construir una identidad que posibilite un cierto poder ordenador en el adentro del complejo como frente al afuera que los homogeniza.

"Acá cualquiera no puede entrar, es como que nos tienen que pedir permiso a nosotros, y menos para sacarnos una de las chicas, las pibas son de acá, y nadie las toca, los otros días nos vinieron a buscar por que Javier se metió con una Pibita de otro barrio, menos mal que se calmaron cuando les mostramos los fierros"28.

El lazo re-ordena, entonces a la hora de marcar un nosotros y otro, y ese otro pareciera estar puesto en la policía, ese vinculo es un ordenador tanto de los espacios como de los vínculos.

Quedan así varias puntas a unir, por un lado, la intolerancia marcada hacia formas o prácticas violentas entre los vecinos, protagonizada por determinadas familias; las bandas de los más chicos (nueva generación de adolescentes) para quienes no existen vínculos para preservar. Pero frente a un determinado accionar de la policía, pareciera que como respuesta a esto pedido, aparece el colectivo posicionándose frente a este otro, que vulneraliza el vivir en ese determinado lugar.

Están operando diferenciaciones internas fuertes, que permiten la expresión de ciertos reclamos, en este caso de orden o control policial, lo cual, a partir de un determinado accionar de la policía opera otra gran diferenciación frente a este otro exterior, que posibilita la construcción de un colectivo.

\section{Destacamento policial: los encargados de garantizar el orden}

"Empezaron a poner en cada sector policías, digamos viviendo, están viviendo ahí, con la gente, con la familia, tienen un departamentito (...) Y ellos controlan un poco ahí, es como decir, ahí hay un policía y hay que tener cuidado"29.

\footnotetext{
${ }^{28}$ Entrevista realizada a uno de los chicos perteneciente al grupo que se analiza, durante el transcurso del trabajo de campo. Año 2002-2003.

${ }^{29}$ Entrevista a habitante del complejo habitacional, en el transcurso del trabajo de campo. Año 2002-2003.
} 


\section{Silvana Martino}

Parece coincidir entonces, la inserción de determinadas instituciones y discursos con las zonas delimitadas como las «mas peligrosas» donde radican las familias antes trabajadas, y que a su vez están sirviendo de fuerte sostén simbólico del administrador del consorcio.

Dentro del Complejo habitacional, las formas estatales de control existen con espacios propios, cedidos por determinados miembros y decisiones. El destacamento policial, dependiente del comando radioeléctrico (Fuerza Departamental) y personal de la comisaría zonal, se encuentra emplazado en el sector del complejo a partir de la demanda de la población de un mayor control, notándose la gran «carencia de la ley», si bien la comisaría de la zona se encuentra a tres cuadras del complejo. Este pedido movilizó y en algún punto enfrento a la población, sintiéndose un fuerte tironeo sobre el espacio que ésta institución debía ocupar, no solo por una lectura explícita del peligro sino también por las relaciones y deudas recíprocas que el administrador del consorcio que dice tener con la Fuerza departamental.

El destacamento policial se encuentra inserto en el entramado del complejo, desde el año 2000 y es el producto de un cambio necesario pero costoso al interior de la fuerza policial ${ }^{30}$.

"Por décadas estuvimos divorciados de la gente por distintos motivos, ya sea políticos, por ser demasiados subordinados a las fuerzas armadas, que se yo...no? entonces, digamos la nueva dinastía, la nueva generación policial, en al cual me incluyo, se ha propuesto acercarse a la comunidad, entonces para organizarlo tácticamente se creo 5 bases operativas, y esto es lo que se llama Plan de Seguridad Barrial"31.

Esta institución difiere sustancialmente de las comisarías, tanto en lo que respecta a las tareas administrativas propias, como al vinculo que deben establecer con los vecinos. Siendo una puerta de entrada a los conflictos que se suscitan a diario, para la búsqueda de soluciones preventivas

Pero en la realidad, y en este caso concreto en el complejo habitacional, lo propuesto difiere, no quedando claro para el conjunto población las funciones pensadas para esta nueva figura o para la misma policía encargada de llevar adelante este cambio, se piensa en una delegación de la comisaría cuarta, o que son parte del comando radioeléctrico, por ejemplo. Lo cierto es que la función mas comunitaria no aparece como una cuestión diferenciadora.

La existencia de la policía tampoco parece ser garantía de «ley» sobre todo esto queda evidenciado y se hace explícita en la figura de uno de los policías. Este se constituye en una figura conflictiva, funcional a un sistema que lo produce y lo contiene, para determinadas acciones ${ }^{32}$. Esta figura será motivo, a partir de una situación

\footnotetext{
${ }^{30}$ El 19 de diciembre de 1997, el gobierno provincial encabezado por Eduardo Duhalde dispuso la intervención civil de la policía bonaerense por noventas días a los efectos de encarar un proceso de reforma institucional que permitiera conformar una nueva estructura orgánica funcional del sistema policial...para ello, el gobierno decidió implementar el Plan de reorganización general del sistema integral de seguridad e investigaciones de los delitos de la provincia de Buenos aires (Sain, 2002: 91) Dentro de este marco, se dispone el establecimiento de destacamentos en distintas zonas de la ciudad de Mar del Plata.

${ }^{31}$ Entrevista al Sub Comisario encargado del Destacamento. Año 2002-2003.

${ }^{32}$ Un informante haciendo referencia a estas acciones, nos decía, que inclusive se lo llama de la comisaría de la zona para «apretar» a los que no cantan, o para la detención de algún «difícil».
} 
puntual, de fuertes tensiones al interior del destacamento como con los vecinos.

Estas prácticas policiales finalmente reproducen el estigma de portar antecedentes, o apellido.

"Se las agarran con los que tiene condicional, los busca para que los pibes le hagan algo y ahí los agarran por desacato a la autoridad, a mi hijo le hicieron eso, No solo se la agarran con los pibes sino con los hijos de los detenidos, las hermanas, las madres, por eso cuando salen se los quieren comer vivo. Acá hay un padre que está en Batán y como molestan a los hijos, el tipo ya dijo, cuando salga lo hago boleta"33.

Una madre comenta: «Es re-jodido esto, cada vez está más peligroso». Haciendo referencia a la impunidad con que se maneja la policía para hacer valer su autoridad, quedando delineadas fronteras, que generan impotencia y paralizan cualquier reclamo.

Aparece así, una contradicción fuerte en torno a la figura del policía como garante de cierto orden y más aún que esta figura ya no se corresponde con la tradicional, ligada más a la represión sino a la prevención y vínculo comunitario, como queda ejemplificado en un artículo del diario loca ${ }^{34}$, donde no solo se denuncia los episodios bochornosos de los guardianes del orden, sino que se exige el buen policía, valiéndose para esto del supuesto de la existencia y necesidad de otra función policial. Esto permite suponer que hay un consenso mínimo sobre la necesidad de contar con un cierto orden para la convivencia pero que además es posible contar con una función social que lo garantice. Queda evidenciado al final de la carta publicada, la desconfianza que la policía reproduce con las prácticas diarias, al pedir la reserva de identidad de las familias denunciantes.

Este sintetiza la representación social que existe en el complejo acerca de la institución de control. La cual no encuentra canales para el tratamiento y resolución de los conflictos aunque desde hace unos años exista una organización creada para esto, los foros vecinales de seguridad.

Junto con el nuevo reconocimiento de la necesidad de generar un vínculo entre la policía y la comunidad, quedó prevista en la Ley 12.454 la constitución de Foros de Seguridad para garantizar a través de esta forma institucionalizada, la participación de la comunidad en los asuntos referidos a la seguridad ${ }^{35}$.

Así, una vez más, quedan delineadas fronteras simbólicas dentro del complejo, que por momentos distan de ser muy diferentes a la delimitación formal, pero que operan a la hora de marcar territorializaciones fuertes entre los distintas formas de poner en práctica el derecho a vivir en un determinado lugar como en la puja diaria por romper con una estigmatización que no distingue sino que homogeneiza el no derecho

\footnotetext{
${ }^{33}$ Entrevista a habitante del complejo habitacional. Trabajo de campo año 2002-2003.

${ }^{34}$ Carta de los lectores anónimo. Diario La Capital de Mar del Plata: del 23 de Noviembre de 2002.

${ }^{35}$ Así quedo dispuesto la constitución tanto del Foro vecinales de seguridad, los foros Municipales de Seguridad, los Foros Departamentales de Seguridad y los Defensores Municipales de la Seguridad. Los foros Vecinales de Seguridad actuarían en el ámbito territorial de cada comisaría integrante de las Policías departamentales de Seguridad, y estarían integrados por aquellas organizaciones y entidades comunitarias no gubernamentales, de reconocida participación social e interesadas en la seguridad pública que actúan en el ámbito territorial (Sain, 2002)
} 


\section{Silvana Martino}

\section{A modo de cierre...}

Estas redistribución, deudas y contra favores que se constituyen en la cotidianeidad de la relación que sostiene el líder con su grupo, marcan líneas o fronteras de sociabilidad dentro de un mismo territorio, en el caso que nos ocupa, un territorio urbano.

Y es por eso que nos resulta interesante situar desde una situación particular, desde una etnografía, una posibilidad de ruptura con una única relación de determinación paralizante de las zonas del estigma, donde pareciera no existir posibilidad de conflicto, resistencia y lucha por parte de los sujetos que lo constituyen.

La homogeneización de pensar en espacios estáticos queda, a su vez conflictuada al reconocer recorridos y límites al interior de este. Son justamente esos límites y fronteras los que permiten que los actores se diferencien y se agrupen para lograrlo y esto le imprime procesos dinamizadores a los territorios.

Estas facciones no solo reconocen sino que amplían sus propios límites, los cuales, no se corresponden necesariamente con un adentro y un afuera, sino que la búsqueda de autoridad, legitimidad y redistribución que invierten las distintas facciones para el logro de sus objetivos les permite interactuar con ese afuera, rompiendo así, con un cierto aislamiento amenazante .

Coincidimos con el planteo de Wacquant en Parias Urbanas ${ }^{36}$, en el análisis comparado entre dos complejos habitacionales, y sobre todo al hacer referencia a uno de ellos, "las taxonomías autóctonas que éstos usan para organizar su rutina diaria distinguen numerosas subunidades dentro de la gran urbanización, que en esencia sólo tiene una existencia administrativa y simbólica, aunque con consecuencias reales. Lo que desde afuera parece un conjunto monolítico es visto por sus miembros como un cúmulo sutilmente diferenciado de microlocalidades"

Suponiendo que son los propios sujetos que lo habitan quienes se apropian e interactúan con las formas impuestas de la materialidad, sí, creemos que existió y aún hoy se reproduce una funcionalidad social de estos espacios como lugares determinados en la trama urbana para la territorialización ${ }^{37}$ del estigma.

Pero a su vez, esto está mostrando que las relaciones de sociabilidad que se establecen al interior de los enclaves urbanos se encuentran hoy enmarcadas en un proceso de degradación relativa de las tradicionales formas de sociabilidad, solidaridad y reciprocidad 3 .

Estas se ven afectadas por determinados grupos que desafían tradicionales formas de convivencia, vulnerando reglas de uso y costumbre en esos ámbitos como no robar dentro del propio barrio o evitar el uso irracional de violencia ${ }^{39}$.

\footnotetext{
${ }^{36}$ WACQUANT, L. Parias Urbanas. Marginalidad en la ciudad a comienzo del milenio. Buenos Aires, Manantial, 2000.

${ }^{37}$ Territorialización en tanto proceso de identificación y estigmatización negativa y violenta de un territorio determinado adentro del espacio urbano, conduciendo a relaciones y prácticas discriminantes en su contra, no sólo por parte de autoridades públicas sino del conjunto del resto del sistema social (Puex, 2003: 41).

${ }^{38}$ v. PUEX, N. Las formas de la Violencia en tiempos de crisis: Una villa Miseria del conurbano bonaerense. Op. cit. y ROSSINI, G «Vagos, Pibes chorros y transformaciones de la sociabilidad en tres barrios periféricos de una ciudad entrerriana» en: ISLA, A.; MIGUEZ, D. (Coord.) Heridas Urbanas. Buenos Aires, FLACSOEdiciones de las ciencias, 2003.

${ }^{39}$ KESSLER, G. «Entre Fronteras Desvanecidas. Lógicas de articulación entre actividades legales e ilegales en los jóvenes» en: GAYOL, S; KESSLER, G. (Comps), Violencia, Delitos y Justicia en la Argentina. Buenos Aires, Manantial-Universidad de Gral. Sarmiento, 2002, pp. 339-354.
} 


\section{Bibliografía}

CAO, J. L; GARCÍA DE ANDREIS, G. Cartografía Invisible. Costumbres de Mar del Plata Buenos Aires, Serie Mitos y Ritos Urbanos, Mito-Logos, 2003.

CLASTRÉS, P. Investigaciones en antropología política. Barcelona, Gedisa, 1980.

CLASTRÉS, P. "Pierre Clastres entrevistado" en: Revista Civilización México DF 1980.

CÁTEDRA PSICOLOGÍA FORENSE Y SEMINARIO TEORÍA CRÍTICA DEL CONTROL SOCIAL. Desarrollo comunitario para la seguridad humana en Latinoamérica. Prevención del conflicto social en el marco doctrinario y técnico de las Naciones Unidas. Facultad de Humanidades y Ciencias de la Educación, Universidad Nacional de La Plata, 1999.

GIGLIA, A. Cultura cívica y movilización popular. El caso de la vivienda interés social en la ciudad de México. México, Congreso de la AMHO, Asociación Mexicana de Historia Oral, Xalapa, Veracruz, 1998.

ISLA, A. Los usos políticos de la identidad. Indigenismo y Estado. Buenos Aires, CONICET-FLACSO, 2002.

ISLA, A; LACARRIEU M; SELBY H. Parando la olla. Transformaciones familiares, representaciones y valores en los tiempos de Menem. Buenos Aires, Grupo NormaFLACSO, 1999.

KESSLER, G. "Entre Fronteras Desvanecidas. Lógicas de Articulación entre Actividades Legales e Ilegales en los Jóvenes" en: GAYOL, S; KESSLER, G. (Comps.). Violencias, Delitos y Justicias en la Argentina Buenos Aires, Manatial/Univesidad de Gral. Sarmiento. 2002, pp. 339-354.

"De Proveedores, Amigos, Vecinos y Barderos: Acerca del Trabajo, Delito y Sociabilidad en Jóvenes del Gran Buenos Aires" en: MURMIS, M. Sociedad y Sociabilidad en la Argentina de los Noventa. Buenos Aires, Biblos, 2002, pp. 137170.

LECHNER, N. La conflictiva y nunca acabada construcción del orden deseado. Madrid, Centro de Investigaciones sociológicas - Siglo XXI, 1986.

HARRIS, M. Antropología Cultural. Madrid, Alianza, 1983.

PUEX, N. "Las Formas de la Violencia en Tiempos de Crisis: Una Villa Miseria del Conurbano Bonaerense" en: ISLA, A.; MIGUEZ, D. (Comps.). Heridas Urbanas. Violencia Delictiva y Transformaciones Urbanas en los Noventa Buenos Aires, FLACSOEdiciones de la Ciencia, 2003, pp. 34-70. 


\section{Silvana Martino}

ROSSINI, G. "Vagos, Pibes Chorros y Transformaciones de la Sociabilidad en Tres Barrios Periféricos de una Ciudad Entrerriana" en: ISLA, A.; MIGUEZ, D. (Comps.). Heridas Urbanas. Violencia Delictiva y Transformaciones Urbanas en los Noventa Buenos Aires, FLACSO-Ediciones de la Ciencia, 2003, pp. 71-113.

SAIN, M. Seguridad, democracia y reforma del sistema policial en la Argentina. Buenos Aires, Fondo de Cultura Económica, 2002.

SOZZO, M (Comp.) Seguridad Urbana. Nuevos problemas, nuevas perspectivas. Santa Fe, Centro de Publicaciones, Secretaría de Extensión, Universidad Nacional del Litoral, 1999.

WACQUANT, L. Parias Urbanas. Marginalidad en la ciudad a comienzo del milenio. Buenos Aires, Manantial, 2001. 